\title{
Changing the Approach: Library and Information Science (LIS) Weaknesses Will Turn into Strength
}

\author{
Gholamreza Fadaie \\ Faculty of Psychology \& Education, University of Tehran, Iran
}

\author{
ghfadaie@ut.ac.ir
}

\begin{abstract}
LIS has been originally defined as a discipline shaped by library as a place. The purpose of this paper is to clarify that this approach is not correct. The author, meanwhile, briefly answers the ten major problems in this regard, made by Nolin \& Astrom. Through content analysis the text claims that the concept of LIS is not derived from library as a place; rather, it originates from the very man's need to information. The author states that the original concept of LIS does not suffer from weakness, if it is considered to have been originated from human need to information. However, the library as a place is a full-size manifestation of this need. Therefore, by changing the approach the major problems may be resolved. The paper provides a clear definition for LIS as a metadiscipline which deals interchangeably with all other fields of study.
\end{abstract}

Keywords: LIS definition; Knowledge management; Changing the LIS approach.

\section{Introduction:}

LIS, for its definition, has witnessed very controversial disputes: it has been defined as a field in crisis (Nolin \& Astrom, 2010, 7) both from its formal beginning as a profession and then as a discipline. From the Western industrial revolution onward, the libraries as intellectual organizations witnessed a large amount of books and documents devoted and donated by some personalities. Those who were responsible to manage them and organize the materials hastily tried to find some codes or rules to classify them in order to answer the urgent and increasing information needs (Vakkari, Cronin, 1996). Whatever they tried, the speed and growth of information productions through books, articles, pictures, and then software's databases and other media increased more, and the necessity of their collection organization got beyond these efforts.

The electronic revolution, beginning with mechanical transmitting signs and symbols, first modeled by Weaver and Shannon (1963), awakened the scholars in library science discipline to find out the original meaning of their main responsibility; along which some information philosophers began to investigate and scrutinize the essence of information. Although the definition was still vague and uncertain, the growth of electronic technology and its effect on information storage

Material published as part of this publication, either on-line or in print, is copyrighted by the Informing Science Institute. Permission to make digital or paper copy of part or all of these works for personal or classroom use is granted without fee provided that the copies are not made or distributed for profit or commercial advantage AND that copies 1) bear this notice in full and 2) give the full citation on the first page. It is permissible to abstract these works so long as credit is given. To copy in all other cases or to republish or to post on a server or to redistribute to lists requires specific permission and payment of a fee. Contact Publisher@InformingScience.org to request redistribution permission. and retrieval made some scholars believe that LIS is mainly technologyoriented.

What really prevented LIS scholars' effort to reach a reasonable definition for LIS, among some other minor reasons, might be the fact that the LIS was believed to be a mere service-oriented job. It meant that the LIS found its origin from library as a place where the people 
in charge had to merely answer the others' simple questions; that is, borrowing and returning the books and documents were the basic services there. Thus, many scholars thought that LIS is only a concept for providing service and library is merely a place for keeping a collection of books and other documents and the librarian's main task is to maintain this collection and prepare access facilities for them whenever needed. On the other hand, trying to find a theoretical basis, others failed to find or introduce a viable definition for LIS. Although a wide variety of studies have been carried out by scholars in this domain, still theoretical shortcomings exist (Hjørland, 2005; Budd, 2001). Some of such scholarly works are as follows (Nolin \& Astrom, 2010, 8):

An alternative viewpoint, though, is to gain understanding on information-related phenomena with only slight reference to applicability (i.e. doing basic research). There are also varying opinions on how LIS research should be performed, making the development of new viewpoints a major theme in the meta-analytical literature, suggesting different epistemological, theoretical and methodological perspectives (e.g. Brookes, 1974; Harris, 1986; Hjørland and Albrechtsen, 1995; Hjørland, 2002a; Wilson, 2003; Ingwersen and Järvelin, 2005).

Among the most recent articles published in 2010, the paper by Nilon and Astrom called: "turning weakness into strength: strategies for future LIS" may be considered as a novel work. They state in this article $(2010,7)$ :

The fragmented nature of LIS can be further exemplified by a variety of views on procedures, approaches and even the raison d'e tre of LIS. A widely accepted motivation for doing LIS research is that it supports the dissemination of relevant information, i.e. a reason for doing research strongly identifying with a particular practice and a professional field. The practice related identity is also strongly related to an identity including a focus on applications oriented research, both in terms of how the field is perceived in academia in general and how research is actually assessed in relation to how it benefits the professional practices.

Nolin and Astrom posed some questions and tried to answer them. Also they claim to have rather found a viable solution in their paper. Before mentioning the ten problems posed by them, they argued that LIS is a discipline with vague definition and fragmented nature. Another factor to them is that the focus of LIS is on practice, i.e. it is practice-based rather being a field with theoretical basis in comparison with some other academic disciplines. Nevertheless, they try to find a strategy to promote the LIS status and argue that for instance features of uncertainty and mutual dependency with other disciplines are among weak characters of LIS which, to them, may turn into strength. Another factor which they see is the existence of many institutions with low mutual dependency (Nolin \& Astrom, 2010, 10). Also they emphasize that this discipline has experienced difficulties through its establishment. An additional factor was that LIS has dependency on several heterogeneous disciplines (Nolin \& Astrom, 2010, 7-10):

Of the 50 European LIS departments surveyed by Larsen (2005), 35 per cent were housed within the arts and humanities, 15 per cent within the social sciences, 13 per cent at communication and media, 9 per cent within business/management, 4 per cent at computer science and 24 per cent within "other". This supplies an image of a quite amazing heterogeneity with a great variety of alliances.

However, they claim (Nolin \& Astrom, 2010, 9):

Our prime interest is in identifying the character of organization of research in the case of LIS and from there to take inventory of a viable strategy.

Also, they emphasize on LIS institutions and they say: 
We see a radical transformation in what kind of training LIS institutions need.

They try to conceptualize or visualize all defects in LIS in ten threats. To them, these threats which to them may be turned to opportunities are first divided into two big categories: "The first four deals with vague boundaries. The remaining six highlights different aspects of fragmentation." The explanation of these problems is as follows (Nolin \& Astrom, 2010, 11-12):

The first problem to them is that LIS comes from practice, which creates a pattern of dependency. The second is that, the heavy reliance of LIS on practice caused its late translation into an academic subject of its own. The third, as they describe, is its late maturity due to the two first problems. They call this as "an internal dependency problem". The fourth problem declares the complicated relationship between library and information science as two separate entities. In this regard they ask: "Are they, e.g. two separate fields with strong connection to each other (Saracevic, 1999 ) or is library science an R \&D activity within information science (Ingewersen, 1992)?"

As they showed, these four problems which to them belong to vague boundaries and uncertainty of LIS definition depend causally one to another. Then, they count the six others as related to the fragmentation problem:

The first is the existence of multitude of subdivisions which they call it mirrors the diversity of topics and heterogeneity problem. The second of this part, as they describe, is that many subdisciplines of LIS have the characteristic of interdisciplinarity, which makes it difficult to generate actual cooperation and interchanging, such as with information and information retrieval research. The third is that LIS nurtures from other disciplines and imports its theoretical ideas. They call this problem as divergent problem. The fourth one to them is "strong traditions of researching information from different perspectives" (Nolin \& Astrom, 2010, 12-13). They call it the competition problem. The fifth problem is "the plenty of LIS research areas and institutions that are small". This may cause, to them, scattered and shallow research attempts not being related to each other. And the last problem in this section is that, some LIS departments are very small whereas some others are very large. To them, depending on the size of LIS departments, they may follow different strategies which results in splitting problem. However the authors hope that these weaknesses may turn to strength if they consider some points. By this, they talk of articulated turns within LIS, which historically may contain Belkin's and Miller's cognitive viewpoint turn, away from positivism of Harris and Wilson, turn to human rather than technology of Saracevic, pragmatic turn of Hjørland, and the extended cognitive viewpoint of Ingewersen and Järvelin ${ }^{1}$. Then they, by identifying different turns, propose new turns as divergent and convergent ones. By describing three turns including divergent, weak convergent and strong convergent turns, they chose strong convergent turn. They suggest that this strong convergent turn must contain six following points (Nolin \& Astrom, 2010, 18):

(1) The new perspective suggests a fresh epistemological foundation that many can share.

(2) The new perspective implies a dramatic (paradigmatic) turn toward an intellectually stimulating perspective.

(3) The convergent turn should appear to suggest a wise career choice.

(4) The convergent turn should build on a strong social or intellectual capital.

(5) Researchers with high stature in the field should propose the convergent turn.

\footnotetext{
${ }^{1}$ - The cognitive turn (Belkin, 1990; Ingwersen, 1992); The informational turn (Wouters, 2007);

The user-centered turn (Zweizig, 1976; Dervin, 1989; Dalrymple, 2001; Talja and Hartel, 2007); The epistemological turn (Brier, 2003); The historical turn (Rayward, 2004); The pragmatic turn (Hjørland, 2002b) (Nolin \& Astrom, 2010, 17).
} 
(6) The new perspective is backed by a strong external tradition.

Then they add (18):

Historical and current examples of turns with a strong convergent potential within LIS could be:

The cognitive viewpoint (Belkin, 1990) following the cognitive revolution within psychology (Miller, 2003).

The turn away from positivism (Harris, 1986; Wilson, 2003).

Turn of direction: starting from the human rather than the technological (Saracevic, 1992).

The pragmatic turn (Hjørland, 2002b).

The extended cognitive viewpoint: Ingwersen and Järvelin (2005).

\section{Discussion}

Although their argument seems to be somehow the result of all researches published before them, since it is published in 2010, and in spite that there are several positive points in their article, it does not seem to solve the inherent weaknesses in this discipline. Because as they have stated too, information and epistemology are applied and used in all other disciplines and may not be allocated only to LIS. This allocation may be considered as the claim without sufficient reason and may be opposed by many other scholars in other fields. Also interaction of LIS with other disciplines, because of the existence of information and knowledge merely in such places as libraries, cannot be considered as a strong and significant theoretical basis. What is important is that although many LIS scholars try their best in many aspects such as epistemology, psychology, history, and so on, LIS cannot still stand up with other disciplines in a right stature and claim for strong theoretical basis in such a way as some other disciplines do. The author believes that if we change our way of looking at LIS, many problems will vanish and many weaknesses will perish. I have discussed in my previous articles (Fadaie, 2008; 2009) that changing the approach will bring a new and strong identity to LIS. I have showed that concept of LIS is not derived from the concept of library as a physical or digital place; rather it is the concept of LIS as information retrieval needs of humans that make people to create library or information center. Ellis, Allen, and Wilson (2002) also state that in building a theory for information science they have not much spoken about human's information needs. I also do not confine the concept of information to LIS. I have studied LIS from two aspects: First, I argue that the concept of LIS derives from the very need of human beings to the information retrieval. This means that the humans for their development in their life need the exact and in-time information. And this cannot be achieved except with retrieving the correct information. Here by retrieving I consider classification as its prerequisite function (Fadaie, 2009):

Moreover, a scholar or a scientist has to classify his knowledge as well as any ordinary man who has to systemize and categorize his work. For example, if somebody needs something to use it for any ordinary purpose it is like when he wants to make a speech, write a paper, or make a book he has to arrange them in a systematic way in order to be able to refer, or to retrieve the ideas. The pagination and table of contents is the result of this notion.

Thus we memorize to remember just in the same way as we learn in order to use. So, our mind is supposed to be the first library, whether or not any library as a place exists. I would like to add to my previous statement that, the concept of memory is not enough to establish the concept of LIS. Because, memory originally belongs to the past: it emphasizes the preservation rather than activity for user satisfaction and it seems to be a little bit passive rather than active. By taking retrieval into consideration for LIS definition, these two defects (being for the past and passiveness) will 
be resolved. Retrieval reminds the intention behind the concept, either from librarian, information specialist, or user.

Categorization and classification as the prerequisites for retrieval are the basic tools in human epistemology. To explain more, when you see a thing you put it in-form ontologically, but when you want to retrieve it epistemologically in order to use it or transmit the concept to others you have to put it in another form in the shape of picture, word or any other signs and symbols and inform them what you mean by them. In this way, if something is unique and there is no example of it in the world, it is impossible, or at least very hard, to make a representation for it in order to use it once more or convey the concept to others. Even if you put a name on it, you must every time show it physically to others so that they understand what you mean. From here, universal, which is the beginning of our epistemology and our concept through our senses, comes to being. Classification as a kind of universal (or better to say, universal is a kind of classification) which is the base for preservation of concepts and sending them to memory begins (Fadaie, 2008, 504):

In the world of reality one sees or touches everything. That is in the realm of ontology every thing is in-form. But when it comes to mind or in the realm of epistemology you can never call it except putting it in a form, too. And you cannot put it in form unless you put it in group or class it in such a way you can retrieve it. Consider that if one thing is absolutely unique, you cannot define it and it is out of mental access. There fore it is evident that man's need for retrieval has led him to locate whatever he has thought or learned in his mind or any other places. Therefore, from the very beginning of the learning process when one encounters things, in remembering them one must have put them in the right places by good categorization or classification. It is a matter of negligence if many do not care about it.

Therefore, information retrieval as the main phenomenon of LIS definition is supposed to be as an intrinsic need of human beings and is always present to him. When we have such a look at LIS, we need not imagine initially the library or information center as a physical body first in order to conceptualize a theory for LIS. Retrieval of information as a principle in our life exists forever. According to this new idea, we may solve the great problem of LIS such as being practicebased in origin. It means that LIS does not begin with those physical centers; rather, it is connected with original needs of human being for information to be retrieved. Just like hospitals which are not considered to be the origin of medicine as a discipline, rather it is the medicine and the original needs of people for hygiene and safety which make it necessary to build hospital. Therefore, we have medical profession and nobody may claim that the medical science has no theoretical basis.

It must be noted that theory and practice are intertwined with each other, opposed to what some philosophers such as Aristotle claim that they are separated from each other. Or as Kant who does not care for pure reason and tries to consider the pragmatic activities of human beings (Resse, 1980). The author believes that, there is no theory which is apart from practice, and also there is no practice which has not arisen from a theory (Fadaie, 2010). It is important to mention that according to traditional logics, any discipline should have subject, problems and objectives. Here, in LIS, retrieval of information is an intrinsic need for people as the subject, and the objective of LIS is to promote the individual and social life situation. Also, other activities related to it must be supposed as problems that we must find a solution to them. That is, it is like other disciplines; because of the growth of technology, its problems may be subject to change during the times and ages, while the discipline itself remains unchanged. The brief history of library may be described as follows (Fadaie, 2008, 506):

When the volume of scientific papers or books increased, the main idea was to make a library, personal or public. One may observe that the first libraries have been personal for 
some individuals, such as kings and emperors and designated scholars. Therefore, the idea of classification as a way to facilitate the retrieval is the foundation of a discipline which now it is called librarianship. In fact, the library has appeared in support of this notion. Retrieval encourages us to organize knowledge. That is, if knowledge is well organized it will be well retrieved, too. So, we practice it in our individual lives by collecting, arranging and putting our necessary commodities somewhere in such a way that we can find them whenever or wherever we want to use them. Therefore, what is no longer of use we throw it away into the waste - basket. So for information retrieval and even in the Internet age the idea of database classification or organization is strong. As Losee (1990) states: Information retrieval is the science of extracting from a database or network of organized [classified] information those items that satisfy a specific need.

The second aspect is the position of LIS in the map of knowledge, and because I have put it near epistemology, we may call it as meta-science or meta-knowledge (Fadaie, 2010, p. 1389). Zins (2007) also has reached such conclusion in his Delphi study and put it in a high position near epistemology.

I have made a definition for LIS which I think clears up some problems such as ambiguity that the above mentioned authors insist on. My definition to LIS goes as follows (Fadaie, 2008, 508):

\section{LIS is the discipline of retrieval of information that deals with concise recognition of knowledge (classification) and considers the cross relationships (vertical \& horizontal) among the scientific and technical terms in order to maintain the exact and fast re- trieval of information and knowledge.}

With this definition, the fragmentation problem will be solved; the challenge which Nolin \& Astrom claim that LIS suffers from it.

Another problem to them comes from the state of interdisciplinarity of LIS and its subsidiaries. In an article published in Persian language (Fadaie, 1389/2010), I argued that regarding LIS as merely interdisciplinary is not correct. Because first we must know that if a field is not considered as a discipline in origin, it cannot be observed as an interdisciplinary one, since being interdisciplinary is dependent first on being a discipline and having an independent identity. Second, we must know that all disciplines, especially in humanities and social sciences, have interdisciplinary characteristics. Of course, it is opposed to statements of positivist paradigm which looks at human beings only in one direction, and considers the knowledge about them in a reductionist manner. Rather, human beings must be studied in a multi-aspect way whose needs must be considered in all ways possible, not only in one aspect (Fadaie, 1389 / 2010). In other words, when we confront with a problem in our life, it may be as the result of psychological, social, cultural, or economical imperfection, and treatment must be carried out in all aspects possible. This means that humanities and social sciences have many aspects and all knowledge in these disciplines are interdisciplinary. Thus, LIS is a discipline with the interdisciplinary characteristics (Fadaie, 1389/2010).

This definition brings all LIS subdivisions under one umbrella, i.e., the main discipline is confined to retrieve the right and exact information for the right user. Therefore, all other subdivisions such as information economic, behavioral study of the users, history and philosophy of science, data-mining, and as such are under the main theme. Also the main domain of LIS does not nurture from other domains, as it has its own theme, which is the retrieval of information. According to Nolin and Astrom, information is common to all other domains, whereas retrieval of information in my proposed definition exclusively belongs to LIS and no other fields share with it. In this definition, all other related domains belong to main theme, i.e. retrieval of information (Fadaie, 2009). Based upon such a concept, I do not think that existence of small and big institu- 
tions or some functionally different ones in this field would harm the LIS position due to fragmentation.

Besides, the advantages provided by the viewpoint of Nolin and Astrom are provided by this definition as well: this new perspective suggests a fresh epistemological foundation. It also implies a paradigmatic turn toward an intellectual perspective and contains a wise career choice. It builds on a strong individual and social capital, since information retrieval with all of its subsets brings a social and capital investment that no other field can compete with it. It is moreover supported by strong tradition. It means that by this definition, retrieval is not imported from other disciplines and is intrinsic to LIS, although information is shared among many fields. The notion of information retrieval is always the same, either in academic context or popular one.

This definition also implies the cognitive viewpoint following the cognitive revolution within psychology as Belkin stated (1990). LIS with this definition is derived from the very human needs and does not belong to technology, as criticized by Saracevic (1992), although technology has affected it in the same way that technology has influenced all other fields and it is far from positivism as Harris and Wilson stated (Nolin \& Astrom, 2010, 18).

\section{Conclusion}

Although the article "Turning weaknesses into strength: strategies for future LIS" is a good and positive one on the way to find a theoretical basis for LIS, it is not sufficient, as grasping to information itself does not solve the problem. Also, finding an optimistic way by considering information as a uniting element to solve fragmentation problem does not help anyway. Convergent turn as they described does not find a solution, too. What I argued here is that changing attitude may sound better. That is, the main problem for LIS as an academic discipline comes from its definition and fragmentation as they explained. To my opinion, the concept of LIS does not come from library and information center as physical or digital places; rather it comes from the very need of human being for retrieval of correct information. Therefore, the theoretical basis for information retrieval is not only practice-based; rather it originates from our need for information in order to develop our life and solve our problems. Also, retrieval of information brings the idea of intention of doer before performing the task. To be precise, if we only consider classification in LIS definition, the intention of providers as well as users may be neglected, while by retrieval it is the person who acts intentionally and knows what he/she does. Retrieval is so central that vitalizes the process and activities performed in LIS including classification, user behavior, information economics, data mining, and so forth. LIS without retrieval seems to be a passive activity, and the library and information centers are like a store, which at their best state look at the past and do not refer to present and future; while by retrieval the intention of the information provider is the core point and acts intentionally to serve others and satisfy them, either in past, now, or future. Unfortunately, although technology has brought a great deal of advantages to us through profusion of information with the notion of speed, the intention of human beings which can communicate with users and act thoughtfully to answer their questions has been neglected and has been substituted with the system.

Also, I argued that theory and practice are not separated from each other, though according to some philosophers they are separated and practice is considered to be in lower level. Nevertheless, LIS has theoretical basis as well as it acts as a profession in such a way that many other disciplines do. According to this new approach and by this definition, all defects seem to be some sort of misconceptions and they are not real ones. 


\section{References}

Belkin, N. J. (1990). The cognitive view point in information science. Journal of Information Science, 16, 11-15.

Budd, J. M. (2001). Information seeking in theory and practice: Rethinking public services in libraries. Reference \& User Services Quarterly, 40(3).

Ellis, D., Allen, D., \& Wilson, T. (1381/2002). Information science and information systems. (R. Fattahi, Trans into Persian). Tehran: National Library of Iran.

Fadaie, G. (2008) In search of new identity for LIS Discipline. Issues in Informing Science and Information Technology, 5.

Fadaie, G. (2009) The LIS discipline or retrieval of information. Issues in Informing Science and Information Technology, 6 .

Fadaie, G. (1389/2010). An introduction to LIS identity (In Persian). Tehran: Public Libraries Foundation. $370 \mathrm{p}$.

Hjørland, B. (1381/2002). Bunyad hay... (Library \& information science: Practice,) (Assd allh Azad, Trans). Tehran, IR: National Library.

Hjørland, B. (2005). Library and information science and the philosophy of science. Journal of Documentation, 61(1), 5-10.

Nolin , J., \& Astrom, F. (2010). Turning weakness into strength: Strategies for future LIS. Journal of Documentation, 66(1), 7-27.

Reese, W. L. (1980). Dictionary of philosophy and religion. NY: Humanity Books.

Saracevic, T. (1992). Information science origin, evolution and relations. In J. Nolin \& F. Astrom. (2010). Turning weakness into strength: strategies for future LIS. Journal of Documentation, 66(1), 7-27.

Vakkari, P., \& Cronin, B. (Eds) (1996). Conception of library and information science: Historical, empirical and theoretical perspectives (pp.5-27). London: Taylor Graham.

Weaver,W., \& Shannon, C. E. (1963). The mathematical theory of communication. Univ. of Illinois Press. http://books.google.com/?id=dk0n_eGcqsUC\&pg=PP1\&dq=inauthor:shannon+inauthor:weaver

Zins, C. (2007). Conception of Information Science. JASIST, 58(3).

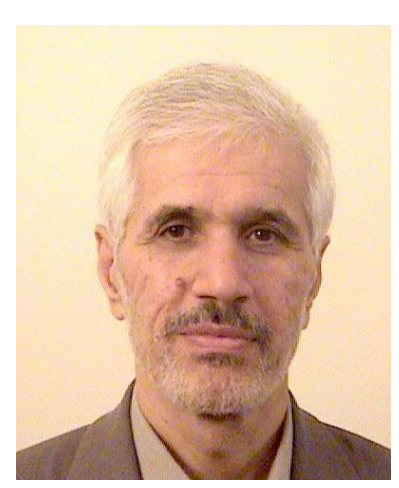

\section{Biography}

Gholamreza Fadaie, Ph.D in LIS is a LIS full professor and the Dean of newly established LIS Faculty, University of Tehran, Iran. He is 65 years old and has about 19 books and more than 30 articles in Persian. Also he has several articles in English and Arabic. Four of his English articles have been published in Cataloging and Classification Quarterly journal in 2004 and 2005. He has some new idea about classification and philosophy of LIS. 